\title{
Assessment of quality of life in patients with visual impairments using a new visual function questionnaire: the VFQ-JII
}

This article was published in the following Dove Press journal:

Clinical Ophthalmology

7 October 2016

Number of times this article has been viewed

\author{
Tadashi Nakano' \\ Motoko Kawashima ${ }^{2}$ \\ Yoshimune Hiratsuka ${ }^{3}$ \\ Hiroshi Tamura ${ }^{4,5}$ \\ Koichi Ono6 \\ Akira Murakami ${ }^{3}$ \\ Kazuo Tsubota ${ }^{2}$ \\ Masakazu Yamada 7,8 \\ 'Department of Ophthalmology, \\ Jikei University School of Medicine, \\ ${ }^{2}$ Department of Ophthalmology, \\ Keio University School of Medicine, \\ ${ }^{3}$ Department of Ophthalmology, \\ Juntendo University Graduate \\ School of Medicine, Tokyo, \\ ${ }^{4}$ Department of Ophthalmology \& \\ Visual Sciences, Kyoto University, \\ ${ }^{5}$ Division of Medical Information \\ Technology \& Administration Planning, \\ Kyoto University Hospital, Kyoto, \\ ${ }^{6}$ Department of Ophthalmology, \\ Juntendo Tokyo Koto Geriatric \\ Medical Center, ${ }^{7}$ National Institute of \\ Sensory Organs, National Hospital \\ Organization Tokyo Medical Center, \\ ${ }^{8}$ Department of Ophthalmology, \\ Kyorin University, Tokyo, Japan
}

Background: The purpose of the present study was to assess the vision-related quality of life (QOL) of visually impaired patients using the Japanese 11-item National Eye Institute Visual Function Questionnaire (VFQ-J11). Comparisons with the 25-item version (VFQ-25) and the EuroQoL Index using a large group of patients with various degrees of impairments and various causative diseases were performed.

Methods: A total of 232 visually impaired Japanese patients were recruited from six ophthalmology departments in Japan. Information on ophthalmic findings and patient backgrounds was collected, and information on QOL and utility assessments was collected from the patients by means of survey questionnaires.

Results: The average age of patients was $69.6 \pm 14.3$ years. Both the vision-related QOL scores (VFQ-25 composite and VFQ-J11) were significantly associated with better and worse visual acuity (VA) in visually impaired subjects (all $P<0.01$ ). VFQ-J11 was comparable to VFQ-25 regardless of causative diseases. VFQ-25 composite and the VFQ-J11 scores were concurrently associated with a range of systemic medical disorders. EuroQoL Index had a significant association with better eye VA $(P<0.01)$, but not with worse eye VA, or any systemic disorders.

Conclusion: VFQ-J11 provides valid data on vision-related QOL and is less of a burden for patients with vision problems.

Keywords: quality of life, utility, visual acuity, visual impairment, VFQ-25, EQ-5D

\section{Introduction}

Normal vision is an important element of health and quality of life (QOL). ${ }^{1}$ Blindness and visual impairments are among the ten most common causes of disability in the US and are associated with both a shorter life expectancy and a lower QOL. ${ }^{2,3}$ Moreover, the visually impaired elderly have an increased risk of falls and fractures, ${ }^{4-6}$ as well as depression. ${ }^{7,8}$ In addition, individuals with impaired vision are at an increased risk of traffic accidents ${ }^{9,10}$ and are more likely to cease or curtail their driving. ${ }^{11}$ Thus, individuals with visual impairments may suffer from functional and psychosocial burdens in various aspects of their daily lives.

The importance of evaluating the burden of disease on QOL from a patientcentered standpoint is widely recognized. For quantitative evaluation of patientreported outcomes, it is essential to apply measurement tools with verified reliability and validity. The National Eye Institute Visual Function Questionnaire (VFQ) was developed to assess the QOL of individuals with visual impairments. It originally comprised 51 items and was later shortened to 25 items and 13 optional items that
Department of Ophthalmology, Kyorin University School of Medicine,

6-20-2 Shinkawa, Mitaka,

Tokyo I8I-86 I I, Japan

Tel +8I 4224755 I I

Fax +8I 422440674

Email yamada@eye-center.org 
generated subscales. ${ }^{12}$ The 25 -item version (VFQ-25) has been validated in many countries, including Japan, ${ }^{13}$ and is widely used as a standard questionnaire for a wide variety of targeted populations, such as the elderly and those with visual impairments. ${ }^{14}$

Although the VFQ-25 is a shorter version of the original VFQ, it still contains 25 essential items and 13 optional items. ${ }^{12,13}$ For patients in a clinical setting, responding to many questions about visual function, sometimes via an interviewer, can impose a substantial burden. The Japanese 11-item National Eye Institute Visual Function Questionnaire (VFQ-J11) was recently developed as a shortened version of the VFQ-25 by using the item response theory. ${ }^{15,16}$ This 11-item questionnaire is expected to be easy to use and less time-consuming, while maintaining good psychometric properties. The purpose of the present study was to assess the vision-related QOL of visually impaired patients using the VFQ-J11 and the VFQ-25. Comparison of these measures using a large group of patients with various degrees of impairments and various causative diseases was performed to determine whether the VFQ-J11 was capable of capturing the vision-related QOL. In addition, we investigated health utility by using the EuroQoL Index (EQ-5D) measure, which is commonly used for the assessment of generic health utility. ${ }^{17,18}$

\section{Participants and methods Participants}

This study was part of a nested study entitled "The Health Economics Research on Vision Screening for Adults", funded by the Ministry of Health, Labour and Welfare of Japan. Data were collected from a multicenter survey conducted between September 2011 and December 2012. A total of 232 visually impaired Japanese patients were recruited from the following six ophthalmology departments in Japan: The National Hospital Organization Tokyo Medical Center, Keio University School of Medicine, Juntendo University Main Hospital, Juntendo Tokyo Koto Geriatric Medical Center, Jikei University, and Kyoto University.

Inclusion criteria were as follows: adult patients (age $\geq 20$ years) who had ocular conditions that resulted in visual impairments, best-corrected visual acuity (VA) $\leq 0.6$ in at least one eye. The inclusion criteria were set according to the visual impairment classification in the Japanese Welfare of Physically Disabled Persons Act. Any disease resulting in visual impairment was acceptable, but limited to chronic and invariable conditions. Patients who had the possibility of improvement through medical or surgical intervention were therefore excluded. Patients who had severe systemic diseases, dementia, psychological diseases, or severe functional impairments such as immobility or limb defects were also excluded. Patients with treatable systemic diseases, such as hypertension, diabetes mellitus, and stroke, were included.

This study protocol was approved by the Institutional Review Board of each clinical site, including Keio University, Tokyo Medical Center, Juntendo University Main Hospital, Juntendo Tokyo Koto Geriatric Medical Center, Jikei University, and Kyoto University. This study was conducted in accordance with the tenets of the Declaration of Helsinki, and the Ethical Guidelines for Medical and Health Research Involving Human Subjects in Japan. The patients received a full explanation of the procedures and provided their written informed consent for participation prior to inclusion in the study.

\section{Methods}

For the 232 patients, information on ophthalmic findings was collected from the responsible physicians. QOL and utility assessment was performed by means of self-reported survey questionnaires. The questionnaires consisted of the Japanese versions of EQ-5D tool and VFQ-25, including the optional questions. ${ }^{13,18}$ The reliability and validity of the Japanese versions of the EQ-5D and VFQ-25 are considered to be comparable to the English versions. ${ }^{13,18}$ The VFQ-J11 score was calculated from the VFQ-25 by including responses to the optional questions. ${ }^{15}$

Decimal VA was examined at a distance of $5 \mathrm{~m}$. Decimal VA values of $<0.01$ were expressed by the following: counting fingers was categorized as an acuity of 0.004 , hand motion as 0.002 , light perception as 0.001 , and no light perception as $0.0005 . .^{19,20}$ For simple linear regression analysis, decimal VA values were converted to the logarithm of the minimum angle of resolution (logMAR).

The causative eye diseases of visual impairment were classified as corneal disease, lens disease, glaucoma, diabetic retinopathy, macular degeneration, degenerative myopia, retinitis pigmentosa, amblyopia, optic nerve atrophy, and others. We selected the top six diseases $(n>10)$ for further analyses.

The VFQ-25 consisted of 25 questions and 13 optional items organized into 12 subscales (one assessing general health and the remainder targeting vision-specific functions) ranging from 0 to $100 .{ }^{12}$ The composite score and the average score across the eleven subscales related to vision-specific functions were a useful summary of visual function. Lower scores indicated a lower QOL. The VFQ-J11 consists of 
$2,5,6,8,11,17,24,25$, and optional items 3,6 , and 8 of the VFQ-25..$^{15}$ We calculated the VFQ-J11 score from the VFQ-25 by including responses to the optional questions. ${ }^{15}$

The EQ-5D is one of the standard methods for assessing the utility value. The EQ-5D is a multi-attribute utility classification system for preferences associated with generic health states. ${ }^{17,18}$ The EQ-5D consists of five questions on mobility, self-care, usual activities, pain/discomfort, and anxiety/depression. Each item is scored on a 3-point scale (none/moderate/extreme) according to the severity of the problem. Individual sets of answers were converted to the utility value. The EQ-5D provides a single index value for clinical and economical evaluation of health care, frequently used for cost-effectiveness analysis.

\section{Statistical analysis}

The associations between various factors and QOL characteristics, including VFQ-25, VFQ-J11, and EQ-5D, were assessed using single linear regression models. Association estimates (beta coefficients) from these models were expressed as the mean difference in grade per unit of change in each factor. All $P$-values were two-tailed. All statistical analyses were performed using SPSS statistical software for Windows, version 21 (IBM Corporation, Armonk, NY, USA). A value of $P<0.05$ was set as the threshold of significance.

\section{Results}

Demographic data are summarized in Table 1. The age of the participants $(n=232)$ enrolled in the study ranged from

Table I Patient demographics $(n=232)$

\begin{tabular}{|c|c|c|}
\hline & Mean \pm SD, $\mathbf{n}$, or $\mathbf{n}(\%)$ & Range or $\mathbf{n}$ \\
\hline Sex (\% male) & 123 (54.9\%) & \\
\hline Age (years) & $69.6 \pm 14.3$ & $20-93$ \\
\hline Better eye BCVA & $\begin{array}{l}\text { Decimal: } 0.34 \\
\text { logMAR: } 0.48 \pm 0.64\end{array}$ & $\begin{array}{l}\text { Decimal: NLP-I.5 } \\
\text { logMAR: }-0.18-3.30\end{array}$ \\
\hline Worse eye BCVA & $\begin{array}{l}\text { Decimal: } 0.03 \\
\text { logMAR: } 1.58 \pm 1.04\end{array}$ & $\begin{array}{l}\text { Decimal: NLP-I.2 } \\
\text { logMAR: }-0.08-3.30\end{array}$ \\
\hline \multicolumn{3}{|l|}{ Causative disease } \\
\hline & ARMD & 53 \\
\hline & Diabetic retinopathy & 34 \\
\hline & Glaucoma & 33 \\
\hline & Corneal disease & 21 \\
\hline & Retinitis pigmentosa & 14 \\
\hline & Degenerative myopia & II \\
\hline & Amblyopia & 7 \\
\hline & Lens disease & 7 \\
\hline & Optic disc atrophy & 5 \\
\hline & Others & 47 \\
\hline
\end{tabular}

Abbreviations: ARMD, age-related macular degeneration; BCVA, best-corrected visual acuity; logMAR, logarithm of the minimum angle of resolution; NLP, no light perception; SD, standard deviation.
20 to 93 years (average, 69.6 \pm 14.3 years) and 123 of the participants were male (54.9\%). The average VA in logMAR units was $0.48 \pm 0.64$ in the better eye and $1.58 \pm 1.04$ in the worse eye (Table 1). The main causes of visual impairment were age-related macular degeneration (53 patients), diabetic retinopathy (34), glaucoma (33), corneal diseases (21), retinitis pigmentosa (14), and degenerative myopia (11). Others (47) included various disorders, such as retinal vein occlusion, retinal artery occlusion, angioid streaks, uveitis, chorioretinal atrophy, macular dystrophy, and phthisis of unknown etiology. A summary of QOL scores is shown in Table 2. The mean VFQ-J11 scores and VFQ-25 composite scores were $49.0 \pm 24.8$ and $51.8 \pm 23.8$, respectively, while the mean EQ-5D utility was $0.74 \pm 0.19$.

We investigated possible associations between QOL parameters and various demographic factors using simple linear regression analysis (Table 3). High scores of VFQ-25 composite, VFQ-J11, and EQ-5D were significantly associated with VA in the better eye (VFQ-25, $P<0.01$; VFQ-J11, $P<0.001$; EQ-5D, $P<0.01$, respectively). For VFQ-25 and VFQ-J11, low scores were significantly associated with VA in the worse eye (VFQ-25, $P<0.01$; VFQ-J11, $P<0.01$, respectively). QOL scores were not associated with sex or age. The VFQ-25 composite and the VFQ-J11 scores were significantly associated with systemic comorbidities, such as hypertension, diabetes mellitus, digestive disorders, neurological disorders, and hearing loss. However, EQ-5D had no significant association with any systemic conditions.

We next investigated the relationships between QOL scores and the better/worse eye VA in detail. The results are summarized in Table 4. When the better eye VA was $>0.6$, scores of both measures of vision-related QOL (VFQ-J11 and VFQ-25) were independent of the worse eye VA (analysis of variance [ANOVA], $P>0.05$ ). However, when the better eye VA was $\leq 0.6$, the vision-related QOL scores of patients decreased with the worse eye VA (ANOVA, $P<0.05$ ), suggesting that the QOL scores were mainly associated with VA in the better eye, but not with the worse eye.

Table 2 Summary of quality of life scores

\begin{tabular}{lllll}
\hline Scores & Mean \pm SD & Median $(I Q R)$ & $\begin{array}{l}\text { Observed } \\
\text { range }\end{array}$ & $\begin{array}{l}\text { Possible } \\
\text { range }\end{array}$ \\
\hline VFQ-JII & $49.0 \pm 24.8$ & $49.3(26.9-69.1)$ & $2.3-100$ & $0-100$ \\
VFQ-25 & $51.8 \pm 23.8$ & $53.5(33.4-7 I . I)$ & $0-95.2$ & $0-100$ \\
EQ-5D & $0.74 \pm 0.19$ & $0.73(0.6 I-1.00)$ & $-0.014-1.00$ & $-0.6-1.0$ \\
\hline
\end{tabular}

Note: Higher values indicate better health for the VFQ-25.

Abbreviations: EQ-5D, EuroQoL Index; IQR, interquartile range; SD, standard deviation; VFQ-JII, Japanese II-item National Eye Institute Visual Function Questionnaire; VFQ-25, 25-item National Eye Institute Visual Function Questionnaire. 
Table 3 Associations between quality of life parameters and various demographic factors

\begin{tabular}{|c|c|c|c|c|c|c|}
\hline \multirow[t]{2}{*}{ Parameters } & \multicolumn{2}{|c|}{ VFQ-25 composite score } & \multicolumn{2}{|l|}{ VFQ-JII score } & \multicolumn{2}{|l|}{ EQ-5D score } \\
\hline & Slope $(95 \% \mathrm{Cl})$ & $P$-value & Slope $(95 \% \mathrm{Cl})$ & $P$-value & Slope $(95 \% \mathrm{Cl})$ & $P$-value \\
\hline Age & $-0.12(-0.34,0.10)$ & 0.27 & $-0.17(-0.40,0.06)$ & 0.15 & $0.000(-0.002,0.001)$ & 0.77 \\
\hline Sex & $-5.6(-11.8,0.59)$ & 0.08 & $-3.84(-10.4,2.79)$ & 0.26 & $0.028(-0.022,0.077)$ & 0.27 \\
\hline \multicolumn{7}{|l|}{ Visual acuity } \\
\hline Better-eye BCVA (logMAR) & $-20.3(-24.4,-16.2)$ & $<0.01$ & $-25.9(-29.7,-22.1)$ & $<0.01$ & $-0.108(-0.144,-0.073)$ & $<0.001$ \\
\hline Worse-eye BCVA (logMAR) & $-6.95(-9.80,-4.11)$ & $<0.01$ & $-6.06(-9.13,-2.99)$ & $<0.01$ & $-0.018(-0.04 I, 0.005)$ & 0.12 \\
\hline \multicolumn{7}{|l|}{ Systemic comorbidities } \\
\hline Hypertension & $-6.64(-13.1,-0.22)$ & 0.04 & $-6.69(-13.6,-0.17)$ & 0.04 & $-0.037(-0.087,0.014)$ & 0.16 \\
\hline Angina & $5.79(-7.58,19.2)$ & 0.39 & $4.36(-9.60,18.3)$ & 0.54 & $0.026(-0.079,0.13)$ & 0.62 \\
\hline Diabetes mellitus & $-7.12(-13.9,-0.38)$ & 0.04 & $-7.86(-14.9,-0.74)$ & 0.03 & $-0.036(-0.089,0.017)$ & 0.18 \\
\hline Cancer & $4.90(-13.1,22.9)$ & 0.59 & $2.62(-16.1,21.4)$ & 0.78 & $-0.10(-0.24,0.038)$ & 0.15 \\
\hline Kidney disorder & $-9.07(-23.5,5.38)$ & 0.22 & $-7.49(-23.3,8.30)$ & 0.35 & $-0.048(-0.16,0.066)$ & $0.4 I$ \\
\hline Digestive disorder & $-28.8(-52.1,-5.43)$ & 0.02 & $-31.2(-59.3,-3.14)$ & 0.03 & $-0.087(-0.27,0.010)$ & 0.36 \\
\hline Respiratory disorder & $-11.9(-39.1,15.3)$ & 0.39 & $-13.9(-42.3,14.3)$ & 0.33 & $-0.094(-0.31,0.12)$ & 0.38 \\
\hline Neurological disorder & $-52.1(-98.6,-5.65)$ & 0.03 & -5 I.I $(-99.6,2.57)$ & 0.04 & $0.11(-0.15,0.36)$ & 0.42 \\
\hline Stroke & $-4.21(-22.2,13.8)$ & 0.65 & $0.62(-19.6,20.8)$ & 0.95 & $-0.021(-0.16,0.12)$ & 0.77 \\
\hline Hearing loss & $-27.3(-48.2,-6.4 I)$ & 0.01 & $-26.1(-50.5,-1.67)$ & 0.04 & $-0.163(-0.33,0.002)$ & 0.053 \\
\hline
\end{tabular}

Abbreviations: BCVA, best-corrected visual acuity; Cl, confidence interval; EQ-5D, EuroQoL Index; logMAR, logarithm of the minimum angle of resolution; VFQ-25, 25item National Eye Institute Visual Function Questionnaire; VFQ-JI I, Japanese I I-item National Eye Institute Visual Function Questionnaire.

We also examined QOL parameters by causative disease (Table 5). Although patients with glaucoma had the lowest VFQ-J11 score and VFQ-25 composite score compared with the other ocular diseases, they were not statistically significant (ANOVA, $P>0.05$ ). Vision-related QOL scores

Table 4 Quality of life parameters based upon the BCVA of the better/worse eye

\begin{tabular}{|c|c|c|c|c|}
\hline \multirow[t]{2}{*}{ Number of subjects } & & \multicolumn{3}{|c|}{ Worse eye BCVA } \\
\hline & & $\leq 0.3$ & $0.4-0.6$ & $0.7 \leq$ \\
\hline Better eye & $\leq 0.3$ & 88 & & \\
\hline \multirow[t]{2}{*}{ BCVA (decimal) } & $0.4-0.6$ & 40 & 6 & \\
\hline & $\overline{0.6<}$ & 75 & 15 & 8 \\
\hline \multirow[t]{2}{*}{ VFQ-25 composite score } & & \multicolumn{3}{|c|}{ Worse eye BCVA } \\
\hline & & $\leq 0.3$ & $0.4-0.6$ & $0.7 \leq$ \\
\hline Better eye & $\leq 0.3$ & $36.3 \pm 18.5$ & & \\
\hline \multirow[t]{2}{*}{ BCVA (decimal) } & $0.4-0.6$ & $48.4 \pm 22.1$ & $55.4 \pm 13.1$ & \\
\hline & $0.6<$ & $66.4 \pm 20.5$ & $68.2 \pm 15.1$ & $70.5 \pm 18.0$ \\
\hline \multirow[t]{2}{*}{ VFQ-JII score } & & \multicolumn{3}{|c|}{ Worse eye BCVA } \\
\hline & & $\leq 0.3$ & $0.4-0.6$ & $0.7 \leq$ \\
\hline Better eye & $\leq 0.3$ & $28.7 \pm 18.3$ & & \\
\hline \multirow[t]{2}{*}{ BCVA (decimal) } & $0.4-0.6$ & $47.7 \pm 19.6$ & $51.2 \pm 15.8$ & \\
\hline & $0.6<$ & $68.0 \pm 15.9$ & $65.1 \pm 17.8$ & $71.2 \pm 15.2$ \\
\hline \multirow[t]{2}{*}{ EQ-5D score } & & \multicolumn{3}{|c|}{ Worse eye BCVA } \\
\hline & & $\leq 0.3$ & $0.4-0.6$ & $0.7 \leq$ \\
\hline Better eye & $\leq 0.3$ & $0.65 \pm 0.17$ & & \\
\hline \multirow[t]{2}{*}{ BCVA (decimal) } & $0.4-0.6$ & $0.73 \pm 0.17$ & $0.67 \pm 0.11$ & \\
\hline & $0.6<$ & $0.82 \pm 0.18$ & $0.82 \pm 0.15$ & $0.88 \pm 0.14$ \\
\hline
\end{tabular}

Note: Data presented as number of subjects or mean \pm standard deviation.

Abbreviations: BCVA, best-corrected visual acuity; EQ-5D, EuroQoL Index; SD, standard deviation; VFQ-25, 25-item National Eye Institute Visual Function Questionnaire; VFQ-JII, Japanese II-item National Eye Institute Visual Function Questionnaire.
(VFQ-J11 and composite VFQ-25) were mainly dependent on VA levels in the better eye for all causative diseases. The utility value determined by EQ-5D showed a low variation for VA groups regardless of causative diseases (ANOVA, $P>0.05)$.

\section{Discussion}

We have assessed QOL and the utility of visually impaired subjects with various backgrounds by means of survey questionnaires consisting of the EQ-5D, VFQ-25, and VFQ-J11. Both VFQ-25 composite scores and VFQ-J11 scores were significantly associated with the better eye VA and worse eye VA. However, EQ-5D scores showed a significant association with the VA of the better eye, but not the worse eye. The VFQ-25 composite and VFQ-J11 scores were concurrently associated with a range of systemic disorders among the visually impaired subjects, while the EQ-5D scores were not associated with any systemic disorders. Our results are consistent with previous studies that reported that EQ-5D is not sensitive enough to assess the impact of the severity of ocular diseases on the QOL. ${ }^{21,22}$

We then examined the possible relationships between QOL and the better/worse eye VA. Our results confirmed that the VA of the better eye predominantly affected the QOL of visually impaired individuals. ${ }^{23}$ Both vision-related QOL measures (VFQ-25 and VFQ-J11) indicated that their scores were independent of the worse eye VA, when the better eye VA was $>0.6$. However, when the better eye VA 
Table 5 QOL scores classified according to causative diseases

\begin{tabular}{lllllllll}
\hline & BCVA & & $\begin{array}{l}\text { Corneal } \\
\text { disease }\end{array}$ & $\begin{array}{l}\text { Retinitis } \\
\text { pigmentosa }\end{array}$ & $\begin{array}{l}\text { Diabetic } \\
\text { retinopathy }\end{array}$ & Glaucoma & $\begin{array}{l}\text { Macular } \\
\text { degeneration }\end{array}$ & $\begin{array}{l}\text { Degenerative } \\
\text { myopia }\end{array}$ \\
\hline Number of & Total & & 21 & 14 & 34 & 33 & 53 & 1 \\
subjects & BCVA group & $\leq 0.3$ & 8 & 2 & 19 & 14 & 12 & 6 \\
& & $0.4-0.6^{\mathrm{a}}$ & 5 & 6 & 11 & 6 & $1 \mathrm{I}$ & 2 \\
& & $0.6<$ & 8 & 6 & 4 & 13 & 30 & 3 \\
VFQ-JII score & Total & & $57.8 \pm 25.3$ & $50.7 \pm 21.4$ & $40.3 \pm 23.6$ & $36.4 \pm 25.7$ & $55.1 \pm 23.3$ & $45.9 \pm 23.6$ \\
(mean \pm SD) & BCVA group & $\leq 0.3$ & $40.0 \pm 23.9$ & $32.8 \pm 9.6$ & $31.7 \pm 22.2$ & $16.9 \pm 16.7$ & $23.2 \pm 11.8$ & $28.1 \pm 11.9$ \\
& & $0.4-0.6^{\mathrm{a}}$ & $57.8 \pm 26.2$ & $40.7 \pm 19.7$ & $44.6 \pm 18.0$ & $40.4 \pm 21.4$ & $53.4 \pm 18.7$ & $56.6 \pm 8.0$ \\
& & $0.6<$ & $72.9 \pm 17.5$ & $66.7 \pm 15.1$ & $69.2 \pm 20.6$ & $57.4 \pm 18.1$ & $69.0 \pm 13.0$ & $74.4 \pm 10.5$ \\
VFQ-25 & Total & & $49.1 \pm 31.8$ & $52.8 \pm 17.9$ & $44.4 \pm 21.2$ & $41.8 \pm 24.8$ & $58.6 \pm 22.8$ & $54.7 \pm 21.9$ \\
composite score & BCVA group & $\leq 0.3$ & $35.4 \pm 29.3$ & $40.3 \pm 18.6$ & $37.0 \pm 20.2$ & $27.7 \pm 17.2$ & $34.9 \pm 12.3$ & $38.7 \pm 13.7$ \\
(mean \pm SD) & & $0.4-0.6^{\mathrm{a}}$ & $46.0 \pm 32.9$ & $45.7 \pm 14.9$ & $48.9 \pm 17.0$ & $39.1 \pm 24.8$ & $54.5 \pm 24.9$ & $64.9 \pm 6.1$ \\
& & $0.6<$ & $64.6 \pm 30.4$ & $64.2 \pm 16.3$ & $67.2 \pm 20.3$ & $58.2 \pm 23.1$ & $69.7 \pm 17.1$ & $80.1 \pm 8.4$ \\
EQ-5D score & Total & & $0.71 \pm 0.18$ & $0.74 \pm 0.18$ & $0.66 \pm 0.15$ & $0.71 \pm 0.18$ & $0.81 \pm 0.18$ & $0.76 \pm 0.17$ \\
(mean \pm SD) & BCVA group & $\leq 0.3$ & $0.70 \pm 0.16$ & $0.60 \pm 0.02$ & $0.63 \pm 0.17$ & $0.63 \pm 0.18$ & $0.70 \pm 0.22$ & $0.66 \pm 0.09$ \\
& & $0.4-0.6^{\mathrm{a}}$ & $0.72 \pm 0.17$ & $0.64 \pm 0.14$ & $0.68 \pm 0.09$ & $0.68 \pm 0.06$ & $0.79 \pm 0.19$ & $0.79 \pm 0.29$ \\
& & $0.6<$ & $0.70 \pm 0.23$ & $0.89 \pm 0.12$ & $0.78 \pm 0.15$ & $0.81 \pm 0.16$ & $0.86 \pm 0.14$ & $0.93 \pm 0.12$ \\
\hline
\end{tabular}

Notes: VA group classified using the better eye best-corrected visual acuity BCVA (decimal). ${ }^{\mathrm{D} D a t a}$ shown as range.

Abbreviations: BCVA, best-corrected visual acuity; EQ-5D, EuroQoL Index; QOL, quality of life; VFQ-JII, Japanese II-item National Eye Institute Visual Function Questionnaire; VFQ-25, 25-item National Eye Institute Visual Function Questionnaire.

was $\leq 0.6$, their scores decreased with the worse eye VA. ${ }^{24}$ Our data also showed that the decline in QOL scores was present even with unilateral modest visual impairment, with no threshold effect in VFQ-25 and VFQ-J11. ${ }^{25}$

We also investigated the relationship between QOL parameters and causative eye diseases and found that causative diseases affected vision-related QOL to a limited degree. Generally, vision-related QOL scores correlated with the better eye VA for all causative diseases. Although statistically not significant, vision-related QOL scores for glaucoma patients were low, even among individuals with the same VA level. This may be because glaucoma patients have greater visual field defects than do other visually impaired participants. ${ }^{26} \mathrm{We}$ also found that VFQ-J11 and VFQ-25 scores varied more widely than EQ-5D scores, suggesting that the VFQ-J11 and VFQ-25 are equally useful for evaluating QOL in severely visually impaired patients, regardless of the causative disease.

This study has some limitations. Although we intended to enroll various visually impaired patients from six ophthalmology departments, the causative diseases of visual impairments might not be a representative sampling of the Japanese population. We calculated the VFQ-J11 from the completed VFQ-25 in the study to avoid repetition. The VFQJ11 scores might be different if the VFQ-J11 was completed as a standalone instrument. In addition, we did not determine the associations between the QOL scores and visual field defects. For this purpose, visual function indices such as the
Functional Vision Score, which includes visual field evaluation, should, in the future, be compared with QOL scores. ${ }^{27}$

\section{Conclusion}

In summary, we found that both VFQ-25 composite and VFQ-J11 scores were significantly associated with the better eye and worse eye VA in visually impaired patients, and that they were sensitive enough to evaluate the QOL in visually impaired patients, regardless of the causative diseases. These results suggested that the VFQ-J11 and VFQ-25 are equally useful indicators of vision-related QOL. Considering that VFQ-J11 is less than half as long as the VFQ-25, the VFQJ11 provides valid data for vision-related QOL, while being less of a burden for patients.

\section{Acknowledgments}

The authors thank Prof Shunichi Fukuhara, Department of Epidemiology and Healthcare Research, Kyoto University, for permission to use the VFQ-J11, and for helpful discussions.

This work was supported by a grant from the Ministry of Health, Labour, and Welfare of Japan, and a grant from the Japan Ophthalmologists Association.

\section{Author contributions}

NT, recruitment of patients; MK, recruitment of patients, statistical analyses, and drafting of tables; HY, recruitment of patients, statistical analyses during manuscript revision; 
HT, recruitment of patients; analyses and interpretation of data; OK, recruitment of patients, analyses, and interpretation of data; MA, recruitment of patients, manuscript revision for important intellectual content; KT, recruitment of patients, manuscript revision for important intellectual content; and MY, conception and design of the study, guidance of the analyses, manuscript revision. All authors contributed toward data analysis, drafting and critically revising the paper, read and approved the final version to be published, and agree to be accountable for all aspects of the work.

\section{Disclosure}

The authors report no conflicts of interest in this work.

\section{References}

1. Vu HT, Keeffe JE, McCarty CA, Taylor HR. Impact of unilateral and bilateral vision loss on quality of life. Br J Ophthalmol. 2005;89(3): 360-363.

2. Swanson MW, McGwin G. Visual impairment and functional status from the 1995 National Health Interview Survey on Disability. Ophthalmic Epidemiol. 2004;11(3):227-239.

3. McCarty CA, Nanjan MB, Taylor HR. Vision impairment predicts 5 year mortality. Br J Ophthalmol. 2001;85(3):322-326.

4. Dargent-Molina P, Favier F, Grandjean H, et al. Fall-related factors and risk of hip fracture: the EPIDOS prospective study. Lancet. 1996; 348(9021):145-149.

5. Felson DT, Anderson JJ, Hannan MT, Milton RC, Wilson PW, Kiel DP. Impaired vision and hip fracture. The framingham study. J Am Geriatr Soc. 1989;37(6):495-500.

6. Ivers RQ, Norton R, Cumming RG, Butler M, Campbell AJ. Visual impairment and risk of hip fracture. Am J Epidemiol. 2000;152(7): 633-639.

7. Meuleners LB, Hendrie D, Fraser ML, Ng JQ, Morlet N. The impact of first eye cataract surgery on mental health contacts for depression and/or anxiety: a population-based study using linked data. Acta Ophthalmol. 2013;91(6):e445-e449.

8. Tsai SY, Cheng CY, Hsu WM, Su TP, Liu JH, Chou P. Association between visual impairment and depression in the elderly. $J$ Formos Med Assoc. 2003;102(2):86-90.

9. Owsley C, McGwin G Jr. Vision impairment and driving. Surv Ophthalmol. 1999;43(6):535-550.

10. Meuleners LB, Hendrie D, Lee AH, Ng JQ, Morlet N. The effectiveness of cataract surgery in reducing motor vehicle crashes: a whole population study using linked data. Ophthalmic Epidemiol. 2012;19(1):23-28.
11. Fraser ML, Meuleners LB, Ng JQ, Morlet N. Driver self-regulation and depressive symptoms in cataract patients awaiting surgery: a crosssectional study. BMC Ophthalmol. 2013;13:45.

12. Mangione CM, Lee PP, Gutierrez PR, Spritzer K, Berry S, Hays RD; National eye institute visual function questionnaire field test investigators. Development of the 25-item National Eye institute visual function questionnaire. Arch Ophthalmol. 2001;119(7):1050-1058.

13. Suzukamo Y, Oshika T, Yuzawa M, et al. Psychometric properties of the 25-item National Eye Institute Visual Function Questionnaire (NEI VFQ-25), Japanese version. Health Qual Life Outcomes. 2005;3:65.

14. Varma R, Wu J, Chong K, Azen SP, Hays RD. Los Angeles Latino Eye Study Group. Impact of severity and bilaterality of visual impairment on health-related quality of life. Ophthalmology. 2006;113(10): 1846-1853.

15. Fukuhara S, Wakita T, Yamada M, Hiratsuka Y, Green J, Oki K. Development of a short version of the visual function questionnaire using item-response theory. PLoS One. 2013;8(9):e73084.

16. Hiratsuka Y, Yamada M, Akune Y, et al. Assessment of vision-related quality of life among patients with cataracts and the outcomes of cataract surgery using a newly developed visual function questionnaire: the VFQ-J11. Jpn J Ophthalmol. 2014;58(5):415-422.

17. Rabin R, de Charro F. EQ-5D: a measure of health status from the EuroQol Group. Ann Med. 2001;33(5):337-343.

18. Tsuchiya A, Ikeda S, Ikegami N, et al. Estimating an EQ-5D population value set: the case of Japan. Health Econ. 2002;11(4):341-353.

19. Holladay JT. Proper method for calculating average visual acuity. J Refract Surg. 1997;13(4):388-391.

20. Kawashima M, Hiratsuka Y, Nakano T, et al. The association between legal Japanese visual impairment grades and vision-related quality of life. Jpn J Ophthalmol. 2016;60(3):219-225.

21. Bozzani FM, Alavi Y, Jofre-Bonet M, Kuper H. A comparison of the sensitivity of EQ-5D, SF-6D and TTO utility values to changes in vision and perceived visual function in patients with primary open-angle glaucoma. BMC Ophthalmol. 2012;12:43.

22. Fenwick EK, Xie J, Ratcliffe J, et al. The impact of diabetic retinopathy and diabetic macular edema on health-related quality of life in type 1 and type 2 diabetes. Invest Ophthalmol Vis Sci. 2012;53(2):677-684.

23. Brown MM, Brown GC, Sharma S, Busbee B, Brown H. Quality of life associated with unilateral and bilateral good vision. Ophthalmology. 2001;108(4):643-647.

24. Hirneiss $\mathrm{C}$. The impact of a better-seeing eye and a worse-seeing eye on vision-related quality of life. Clin Ophthalmol. 2014;8:1703-1709.

25. Chia EM, Mitchell P, Rochtchina E, Foran S, Wang JJ. Unilateral visual impairment and health related quality of life: the Blue Mountains Eye Study. Br J Ophthalmol. 2003;87(4):392-395.

26. Lisboa R, Chun YS, Zangwill LM, et al. Association between rates of binocular visual field loss and vision-related quality of life in patients with glaucoma. JAMA Ophthalmol. 2013;131(4):486-494.

27. Colenbrander A. Assessment of functional vision and its rehabilitation. Acta Ophthalmol. 2010;88(2):163-173.
Clinical Ophthalmology

\section{Publish your work in this journal}

Clinical Ophthalmology is an international, peer-reviewed journal covering all subspecialties within ophthalmology. Key topics include: Optometry; Visual science; Pharmacology and drug therapy in eye diseases; Basic Sciences; Primary and Secondary eye care; Patient Safety and Quality of Care Improvements. This journal is indexed on Submit your manuscript here: http://www.dovepress.com/clinical-ophthalmology-journal

\section{Dovepress}

PubMed Central and CAS, and is the official journal of The Society of Clinical Ophthalmology (SCO). The manuscript management system is completely online and includes a very quick and fair peer-review system, which is all easy to use. Visit http://www.dovepress.com/ testimonials.php to read real quotes from published authors. 